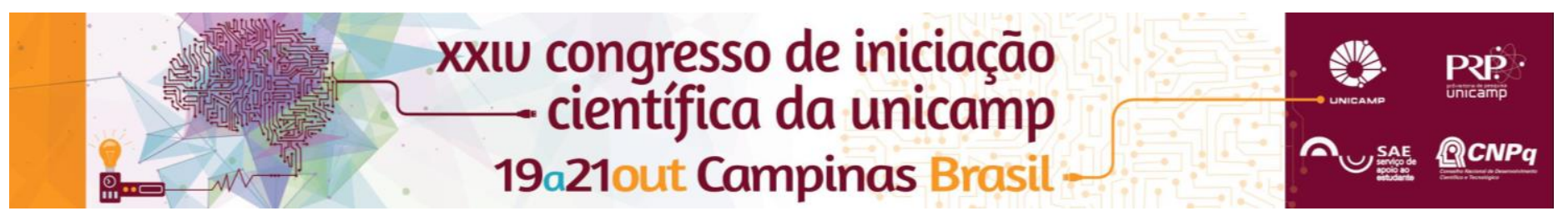

\title{
Treatment of Humeral Shaft Fractures: a prospective, observational study
}

\author{
Angela Katayama*, José Mariolani, Guilherme Mouraria, William Belangero.
}

\begin{abstract}
Despite Humeral Shaft Fractures represent a serious cause of mortality and morbidity, there are few data describing the most common treatment practices and their outcomes in Latin America. A prospective, observational multicenter study has been created to address this critical knowledge gap. This study, focused on the treatment options for humeral shaft fracture, presents the preliminary results from a single center's perspective.
\end{abstract}

\section{Key words:}

Humeral Shaft Fracture, Treatment, Results.

\section{Introduction}

Humeral Shaft Fractures (HSF) represent 1 to $3 \%$ of all fractures in adults, with overall incidence of $14.5 / 100.000$ per year. They follow a bimodal age distribution with peaks around the third and eighth decades. ${ }^{1,2}$ These fractures can be classified according to AO/ OTA as 12-A (simple), 12-B (wedge) and 12-C (complex). Historically, non-surgical treatment has been the standard care for HSFs, and surgical treatment was reserved to specific situations such as open fractures Gustilo II and III, fractures with associated vascular injuries, floating elbow, politrauma or high-energy mechanism trauma, radial nerve injury, segmental fracture, bilateral humeral fracture, pathological fracture and delayed union or malunion. However, advances in surgical techniques and materials, and patient characteristics that prevent an adequate external mobilization such as obesity, are leading to an increase in surgical indications for the treatment of HSFs. The most common surgical techniques are Intramedullary (IM) nails, Minimally Invasive Plate Osteosynthesis (MIPO) and Open Reduction and Internal Fixation (ORIF).

In spite of the present shift towards surgical treatment of HSFs, there is no consensus regarding to the ideal treatment and technique, as each method has its particular advantages, disadvantages and complications. The main purpose of this study is the assessment of HSF treatment in our service, if surgical or non-surgical, the surgical technique used, and results from this treatment.

\section{Results and Discussion}

This prospective, observational study has been approved by the Ethics Committee of FCM-UNICAMP. All patients aged 18 or more, with closed humeral shaft fracture confirmed by radiological image, and attended in our service since January 2016, are being included in the study after signing a written informed consent. Patients under age 18 , with open fracture, politrauma, fractures extended to shoulder and elbow joints and pathological fracture are being excluded. Follow-ups are being done at 15, 42 and 90 days after initial treatment. Functional outcomes are being assessed based on the short version of the Disabilities of the Arm, Shoulder and Hand Outcome questionnaire (Quick DASH $(\circledR)$ ) and Constant score. ${ }^{3,4}$
Data collection is still in progress. In our preliminary results, we observed that most of the fractures $(60 \%)$ were from high-energy mechanism (traffic-related injuries), affecting males under 50 years. Most of the females $(75 \%)$ had low-energy trauma. The mean age of this study was $40.7 \pm 18.93$ years (18 to 66 ). The mean age for males was $29 \pm 14.4$ years (18 to 52) and for females was $58.25 \pm 6.65$ years (50 to 66). 12-A type fractures were the most common (60\%) followed by $12-\mathrm{B}$ type $(40 \%)$. $70 \%$ of the fractures were on the nondominant side.

$90 \%$ of the patients had surgical treatment. From these, on $66.67 \%$ it was used MIPO technique and on $33.33 \%$, ORIF. Clinical evaluations are still under way.

It is also important to emphasize that the sample size is not statistically relevant, yet.

\section{Conclusions}

These are preliminary data and results are not conclusive. Thus far, the treatment type most prevalent in our study is surgical, and the most frequent surgical technique is Minimally Invasive Plate Osteosynthesis (MIPO). However, changes may happen as data collection progresses.

\section{Acknowledgement}

This study was supported by National Counsel of Technological and Scientific Development (Conselho Nacional de Desenvolvimento Científico e Tecnológico CNPq).

\footnotetext{
1 Court-Brown, C.M.; Caesar, B. Epidemiology of adult fractures: A review. Injury. 2006;37(8):691-7.

2 Ekholm, R.; Adami, J.; Tidemark, J.; Tidermark, Hansson, K.; Törnkvist, H.; Ponzer, S. Fractures of the shaft of the humerus. An epidemiological study of 401 fractures. J Bone Joint Surg [Br] 2006;88-B:1469-73.

${ }^{3}$ Constant, C.R.; Murley, A.H. A clinical method of functional assessment of the shoulder. Clin Orthop Relat Res. 1987;(214):160-4.

4 Hudak, P.L.; Amadio, P.C.; Bombardier, C. Development of an upper extremity outcome measure: the DASH (disabilities of the arm, shoulder and hand) [corrected]. The Upper Extremity Collaborative Group (UECG). Am J Ind Med. 1996 Jun;29(6):602-8.
} 